\title{
Laboratory Analysis of Foam Generating Surfactants and Their Thermal Stability for Enhanced Oil Recovery Application
}

\author{
Muhammad Khan Memon ${ }^{1 a}$, Ubedullah Ansari ${ }^{1 b}$, Habib U Zaman Memon ${ }^{1 c}$ \\ RECEIVED ON 17.10.2018, ACCEPTED ON 03.05.2019
}

\begin{abstract}
The residual oil after primary or secondary oil recovery can be recovered by the methods of EOR (Enhanced Oil Recovery). The objective of this study is screening the surfactants that generate maximum stable foam in the presence of brine salinity at $92^{\circ} \mathrm{C}$. Laboratory experiments have been performed to examine and compare the stability of generated foam by individual and blended surfactants in the synthetic brine water. AOS C14-16 (Alpha Olefin Sulfonate) and SDS (Sodium Dodecyl Sulfonate) were selected as main surfactants. Aqueous stability test of AOS $\mathrm{C}_{14-16}$ and SDS with brine water salinity $62070 \mathrm{ppm}$ was performed at $92^{\circ} \mathrm{C}$. AAS (Alcohol

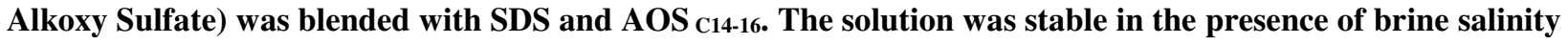
at same conditions. Salt tolerance experimental study revealed that AOS C14-16 did not produce precipitates at $9^{\circ} \mathrm{C}$. Further, the foam stability of surfactant blend was performed. Result shows that, the maximum life time of generated foam was observed by using blend of $0.2 \mathrm{wt} \%$ SDS+0.2wt $\%$ AOS+0.2wt\% AS-1246 and $0.2 \mathrm{wt} \%$ AOS+0.2wt \% IOS $\mathrm{C}_{\mathrm{C} 5-18+0.2 \mathrm{wt} \%} \mathrm{AAS}$ surfactants as compared to the foam generated by individual surfactants. The success of generated foam by these surfactant solutions in the presence of brine water is the primary screening of surfactant stability and foamability for EOR applications in reservoirs type of reservoirs.
\end{abstract}

Key Words: Aqueous Stability, Brine Salinity, Foam Stability, Surfactants, Surfactant Alternating Gas.

\section{INTRODUCTION}

$\mathrm{D}$ uring gas injection, viscous fingering and gravity override problems are introduced. These problems are caused by low viscosity and low density of gas as compared to the other fluids such as oil and water. The problems mentioned during gas injection process can be improved by foam. The injection of foam either by using any EOR method such as FAWAG (Foam Assisted Water Alternating Gas), SAG (Surfactant Alternating Gas), or foam flooding has gained increasing attention by oil industry due to potential advantages over other methods used in EOR [1-4]. The blend of surfactant can generate more foam therefore, improve the foam stability. Bubble size and volume fraction of gas from the generated foam are considered important parameters. These two parameters depend on foam components and application requirements [5].

The SAG injection process is considers as a good method to sweep the residual oil. The process shows

\footnotetext{
${ }^{1}$ Institute of Petroleum and National Gas Engineering, Mehran University of Engineering and Technology, Jamshoro, Pakistan. Email: a muhammad.khan@faculty.muet.edu.pk (Corresponding Author) bubedullah.ansari@faculty.muet.edu.pk, chabib.memon@faculty.muet.edu.pk
}

This is an open access article published by Mehran University of Engineering and Technology, Jamshoro under CC BY 4.0 International License. 
apparent viscosity much higher than its constituent phases: liquid and gas. The foam generated by this method has a mobility much lower than the mobility of gas alone due to high apparent viscosity. Therefore, this process affords an effective means of controlling gas mobility of the displacing fluid [6-9]. The gas mobility is improved by minimizing the relative permeability and increasing the effective gas viscosity. Therefore, the overall sweep efficiency of this injection process is improved [10-13].

In the chemical EOR, anionic surfactants are widely used because of their low adsorption on sandstone reservoirs. AOSc $\mathrm{A}_{12-14}$ anionic surfactant is proved to be an excellent foam insensitive to brine composition and tolerant to presence of crude oil [14]. Nonionic surfactants are used as co surfactants to improve system phase behavior. These types of surfactant are more tolerant to high salinity but cannot reduce much IFT as anionic surfactants. Amphoteric surfactants also known as zwitterionic surfactants are temperature and salinity tolerant. Amphoteric surfactant was used for medium to high viscosity crude oil, Lauryl betaine was blended with 4:1 blend of Neodol67-7PO sulfate and $\mathrm{IOSc}_{15-18}$. The blend was tested in the secondary and tertiary oil recovery with good result of oil displacement because of gas mobility control [15].

Lot of research have been performed on different types of surfactants that generate foam. Also, field testing and implementation were reported using expensive surfactants due to the decline of overall oil production and increases in the oil prices [16]. The blend of different type of surfactants synergistically exhibit better foaming properties than those of individual surfactants. This research deals with single and blended surfactants in the presence of different brine salinity to generate the maximum foam. To achieve the objective of this research study, anionic surfactants

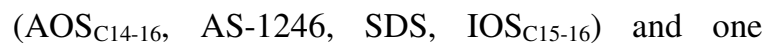
additive AAS are selected. The foam stability and durability of single and blended surfactant solutions with low and high concentrations in the presence of brine water are tested under static conditions. The blended surfactant solutions are beneficial to control the gas mobility and improve the sweep efficiency during the water alternating gas injection process. The usage of surfactant (stable foam generated by single or blended surfactant solutions) minimizes the problems of early gas breakthrough, gravity override and viscous fingering during the water alternating gas injection process. This research is helpful for selecting the surfactant through screening of individual and blended surfactant solutions in the presence of brine water that generates maximum foam. This generated stable foam will help in the gas mobility control during the water alternating gas injection as EOR processes.

\section{MATERIALS}

Five types of surfactants $\mathrm{AOS}_{\mathrm{C} 14-16}$, AS-1246, SDS, $\mathrm{IOS}_{\mathrm{C} 15-18}$ (Internal Olefin Sulfonate), and AAS were used for the foam stability test without further purification. The synthetic brine solution contained Sodium Chloride $(\mathrm{NaCl})$, Magnesium chloride $\left(\mathrm{Mgcl}_{2} \cdot 6 \mathrm{H}_{2} \mathrm{O}\right)$, Potassium chloride $(\mathrm{KCL})$, Sodium bicarbonate $\left(\mathrm{NaHCO}_{3}\right)$, Sodium sulphate $\left(\mathrm{Na}_{2} \mathrm{So}_{4}\right)$ and Calcium Chloride $\left(\mathrm{Cacl}_{2} \cdot 2 \mathrm{H}_{2} \mathrm{O}\right)$ were used with different concentration of single and blended surfactants. Table 1 shows the composition of brine water prepared in the laboratory.

\begin{tabular}{|c|c|}
\hline $\begin{array}{c}\text { TABLE 1. COMPOSITION OF SYNTHETIC } \\
\text { BRINE WATER }\end{array}$ & $\begin{array}{c}\text { Weight } \\
(\mathrm{mg} / \mathrm{liter})\end{array}$ \\
\hline Salt & 23590 \\
\hline Sodium & 37833 \\
\hline Chloride & 408 \\
\hline Calcium & 239 \\
\hline Magnesium & - \\
\hline Potassium & - \\
\hline Bicarbonate & - \\
\hline Sulphate & 62070 \\
\hline Total Salinity &
\end{tabular}

\section{METHODOLOGY}

\subsection{Foam Stability Test}

Concentrated solution of surfactant and brine water was mixed in a glass test tube, agitated and then settled for one hour in an oven at reservoir temperature of $92^{\circ} \mathrm{C}$. The surfactant solution was considered stable when no phase separation or clouds has been observed. Mehran University Research Journal of Engineering and Technology, Vol. 39, No. 2, April 2020 [p-ISSN: 0254-7821, e-ISSN: 2413-7219] 
To achieve the objective of the research study preliminary foam stability test was performed. The aim of this test was to analyze the ability of surfactant to stabilize the foam in the presence of brine salinity at $25^{\circ} \mathrm{C} .10 \mathrm{ml}$ of each surfactant solution was transferred into the $25 \mathrm{ml}$ graduated test tube. The cap of the test tube was tighten. The foam was generated by shaking of the test tube up to 5 minutes. The test tube was settled on the stand to read the generated foam height at the initial stage. At the initial stage, the foam height is measured from top of generated foam in the $25 \mathrm{ml}$ graduated test tube to the level of drained liquid in the test tube. After that, the generated foam stability and longevity was noted with respect to time in minutes. Fig. 1 shows the generated foam by surfactant solutions using $25 \mathrm{ml}$ graduated glass test tubes.
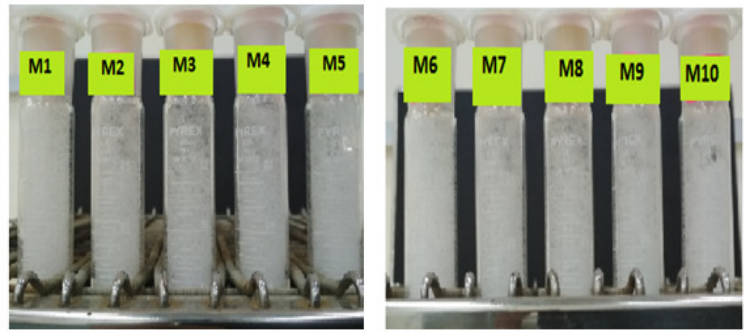

FIG. 1. FOAM GENERATED BY SURFACTANT SOLUTIONS AND FOAM STABILITY

\section{RESULTS AND DISCUSSION 4.1 Foam Generation}

Equal concentration of surfactant SDS was blended with additive AAS to maximize the range of brine salinity and strong foam generation. The test was performed with brine water at $25^{\circ} \mathrm{C}$. Further, the surfactant IOS $_{\mathrm{C} 15-18}$ was blended with equal concentration of AAS and SDS. This blend of surfactant solution was stable at the same conditions.

(1) $\mathrm{M} 1=0.2 \mathrm{wt} \% \mathrm{SDS}+0.2 \mathrm{wt} \% \mathrm{AAS}$

(2) $\mathrm{M} 2=0.2 \mathrm{wt} \% \mathrm{SDS}+0.2 \mathrm{wt} \% \mathrm{IOS}_{\mathrm{C} 15-18}+$ $0.2 \mathrm{wt} \%$ AAS
Fig. 2 shows the generated foam volume of surfactant solution at the initial stage and then decreased with time. $10 \mathrm{ml}$ solution of each sample was prepared in to the $25 \mathrm{ml}$ graduated glass test tube.

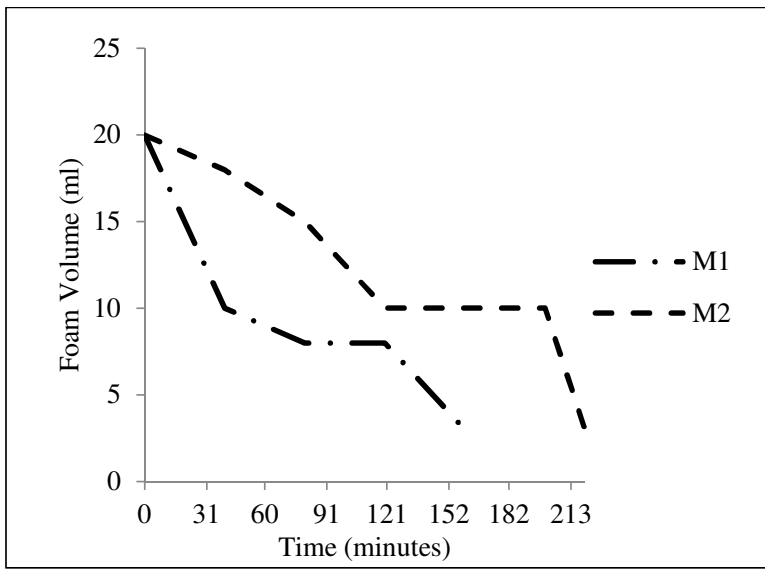

FIG. 2. GENERATED FOAM VOLUME AND ITS STABILITY BY SURFACTANT SOLUTION OF M1AND M2

The foam was generated by shaking of 5 minutes and foam volume was recorded after drain out of liquid from the test tube. About $20 \mathrm{ml}$ foam was generated by M1 surfactant solution, whereas, M2 surfactant solution generated $22 \mathrm{ml}$ foam. Once the foam was generated in the test tube, the generated foam height was decreased due to the force of gravity (liquid drain through the lamellae). The foam volume of M1 was decreased continuously with time. Surfactant solution M2 was stable because of the surfactant SDS was blended with IOS $_{\mathrm{C} 15-18}$ and AAS.

To maximize the foam stability and durability anionic surfactants SDS and AOS $_{\mathrm{C} 14-16}$ were selected as the main surfactants. AS-1246 foamer was blended for stabilizing the maximum foam. Four surfactant solutions were tested for foam generating test. 
(1)

$$
\mathrm{M} 3=0.2 \mathrm{wt} \% \mathrm{SDS}
$$

$\mathrm{M} 4=0.2 \mathrm{wt} \% \mathrm{SDS}+0.2 \mathrm{wt} \%$ AS-1246

(3)

$\mathrm{M} 5=0.2 \mathrm{wt} \% \mathrm{SDS}+0.2 \mathrm{wt} \% \mathrm{IOS}_{\mathrm{c} 15-18}+$

$0.2 w t \%$ AS -1246

$$
\begin{aligned}
& \mathrm{M} 6=0.2 \mathrm{wt} \% \mathrm{SDS}+0.2 \mathrm{wt} \% \mathrm{AOS}_{\mathrm{C} 14-16}+ \\
& 0.2 \mathrm{wt} \% \text { AS-1246 }
\end{aligned}
$$

Fig. 3 shows the foam volume generated from these four individual and blended surfactant solutions.

$22 \mathrm{ml}$ foam was generated from $10 \mathrm{ml}$ solution of M3 individual surfactant. The same volume of foam was generated by surfactant solution of M4 blended surfactant, whereas $24 \mathrm{ml}$ foam was generated from M5 and 25ml foam height from M6 blended surfactant solutions in the graduated test tubes. Foam height generally increases with increase in the surfactant concentration.

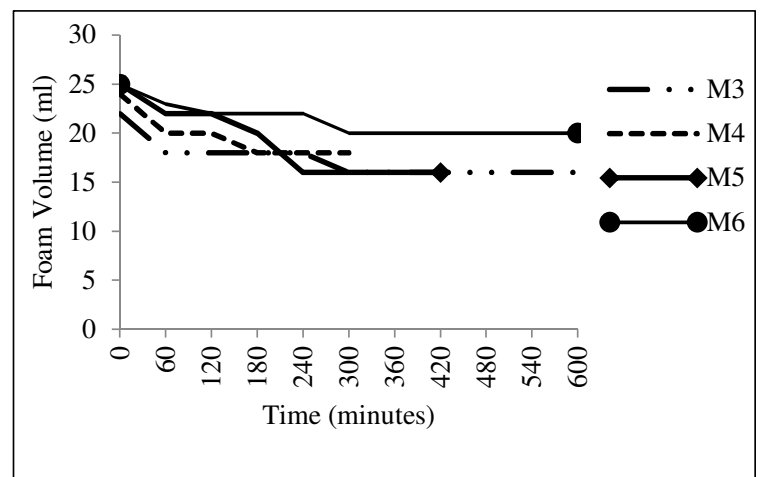

FIG. 3. GENERATED FOAM VOLUME AND ITS STABILITY BY SURFACTANT SOLUTION OF M3, M4, M5 AND M6

The foam volume generated from $10 \mathrm{ml}$ solution of M3 was stable with slowly decreased up to 600 minutes. The foam volume of M4 was decreased in 300 minutes, whereas, the foam volume generated by surfactant solution of M5 and M6 were stable up to 440 and 600 minutes. The solution of M3 was only the single surfactant SDS that has formed good foam volume $20 \mathrm{ml}$ at the initial time. The foam volume was stable and slowly decreased. The $16 \mathrm{ml}$ foam volume was noted in 600 minutes. The foam volume of M6 was more stable as compared to M3, because the SDS was blended with equal concentration of two Mehran University Research Journal of Engineering and Technology, Vol. 39, No. 2, April 2020 [p-ISSN: 0254-7821, e-ISSN: 2413-7219] surfactants $\mathrm{AOS}_{\mathrm{C} 14-16}$ and AS-1246. The $20 \mathrm{ml}$ foam volume was recorded in 600 minutes. The foam volume of M5 was stable up to 420 minutes and generated more foam volume as compared to M4. Further, four surfactant solution of $\mathrm{AOS}_{\mathrm{C} 14-16}$ were blended with $\mathrm{IOS}_{\mathrm{C} 15-18}$, AS-1246 and AAS. The test was performed with brine water at $25^{\circ} \mathrm{C}$.

(2) $\mathrm{M} 8=0.2 \mathrm{wt} \% \mathrm{AOS}_{\mathrm{C} 14-16}+0.2 \mathrm{wt} \% \mathrm{AS}-1246$

(3) $\mathrm{M} 9=0.2 \mathrm{wt} \% \mathrm{AOS}_{\mathrm{C} 14-16}+0.2 \mathrm{wt} \%$ AAS

(4) $\mathrm{M} 10=0.2 \mathrm{wt} \% \mathrm{AOS}_{\mathrm{C} 14-16}+0.2 \mathrm{wt} \% \mathrm{IOS}_{\mathrm{C} 15-18}$ $+0.2 \mathrm{wt} \%$ AAS

$25 \mathrm{ml}$ foam volume was generated from $10 \mathrm{ml}$ surfactant solution of M7 and M8. Surfactant solution M8 was the blend of $\mathrm{AOS}_{\mathrm{C} 14-16}$ and AS-1246 foam stabilizer but the solution of M7 was single surfactant AOS $_{\mathrm{C} 14-16}$ only. Fig. 4 shows foam volume generated from four surfactant solution.

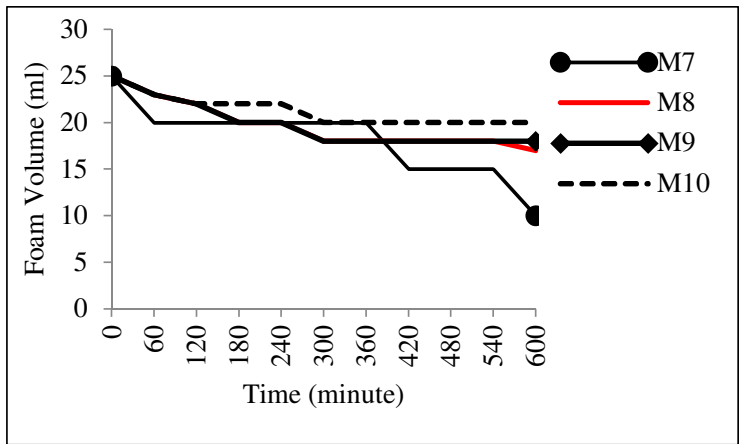

FIG. 4. GENERATED FOAM VOLUME AND ITS STABILITY BY SURFACTANT SOLUTION OF M7, M8, M9 AND M10

Surfactant solution of M10 produced good foam volume and was stable with long time duration. The surfactant solution M9 produced $20 \mathrm{ml}$ foam, whereas, M10 surfactant solution produced $22 \mathrm{ml}$ foam. The same foam volume was generated as foam generated by M1 and M2 surfactant solution. The foam volume generated from M9 was stable up to 160 minutes, and the foam volume of M10 was stable up to 220 minutes. The solution of M7 was only the $\mathrm{AOS}_{\mathrm{C} 14-16}$ that has formed good foam volume $25 \mathrm{ml}$ at the initial time. The foam volume was stable with long duration and slowly decreased with time. M8 solution was stable with long duration. At 600 minutes the foam volume of M8 
surfactant solution was $18 \mathrm{ml}$ whereas, at the same time $10 \mathrm{ml}$ foam volume was noted by M7 surfactant solution. Surfactant solution M10 was considered as good foamer. The foam generated by the surfactant solution M10 is more stable due to high disjoining pressure and the electrostatic repulsion between the surfactant and enclosed bubble surfaces [17]. Surfactant solution either individual or blended surfactants that generates foam with maximum volume at the initial stage are considered to have a good foamability and those tested surfactant solution which produced foam with a less initial volume are considered to have a poor foamability. Less amount of generated foam by surfactant solution provides a moderate reduction in a gas mobility due to the coarsely textured foam. This type of generated foam contains small number of lamellae with large bubbles. Foam height at the initial stage by surfactant solutions increases due to the increase in kinetic energy. It leads that, the adsorption of surfactant molecules on the interface increases, so that the foam height increases.

\section{CONCLUSIONS}

(i) No precipitation was observed by tested individual and blended surfactant solution in brine water at $92^{\circ} \mathrm{C}$.

(ii) The blended surfactant solution of M6 (0.2wt $\%$ SDS, $0.2 \mathrm{wt} \%$ AOS, $0.2 \mathrm{wt} \%$ AS1246) and M10 (0.2wt\% AOS, $0.2 \mathrm{wt} \%$ $\mathrm{IOS}_{\mathrm{C} 15-18}, \quad 0.2 \mathrm{wt} \%$ AAS) improves the performance of generated foam and its stability.

(iii) Blend of surfactants can lead to generate more stable foam than foam generated by individual surfactants.

(iv) The study of surfactant structure with effects of head and tail group is recommended.

\section{ACKNOWLEDGMENT}

This work was carried out as part of the Enhanced Oil Recovery at the Institute of Petroleum \& Natural Gas Engineering, Mehran University of Engineering \& Technology Jamshoro, Sindh Pakistan, which is gratefully acknowledged.

\section{REFERENCES}

[1] Li, R.F., Yan, W., Liu, S., Hirasaki, G., and Miller, C.A., "Foam Mobility Control for Surfactant Enhanced

Oil

Recovery", Society of Petroleum Engineers Journal, Vol. 15, No. 4, pp. 928-942, 2010.

[2] Guo, H., Faber, M.J., Buijse, M.A., and Zitha, P.L., "A Novel Alkaline-Surfactant Foam EOR Process", Society of Petroleum Engineers Conference on Enhanced Oil Recovery Kuala Lumpur, Malaysia, 19-21 July, 2011.

[3] Saputra, D., Bae, W., Permadi, A., Muslim, M., Pham, T., Efriza, I., and Gunadi, T., "Optimization of Surfactant Concentration to the Foam Generation and Swelling Ratio of CO Foam Flooding in Light Oil Reservoir", Society of Petroleum Engineers Asia Pacific Oil and Gas Conference and Exhibition, Jakarta, Indonesia, 22-24 October, 2013.

[4] Bera, A., Ojha, K., and Mandal, A., "Synergistic Effect of Mixed Surfactant Systems on Foam Behavior and Surface Tension", Journal of Surfactants and Detergents, Vol. 16, No. 4, pp. 621-630, 2013.

[5] Sakai, T., and Kaneko, Y., "The Effect of Some Foam Boosters on the Foamability and Foam Stability of Anionic Systems", Journal of Surfactants and Detergents, Vol. 7, No. 3, pp. 291-295, 2004.

[6] Patzek, T., "Description of Foam Flow in Porous Media by the Population Balance Method", Surfactant-Based Mobility Control, ACS Symposium Series, Volume 373, pp. 326-341, 1985. 
[7] Kovscek, A., and Radke, C., "Fundamentals of Foam Transport in Porous Media", Technical Report, Lawrence Berkeley Lab, CA, United States, 1994.

[8] Schramm, L.L., "Foams: Fundamentals and Applications in the Petroleum Industry", ACS Publication, Vol. 242, 1994.

[9] Rossen, W., "Foams in Enhanced Oil Recovery", Foams: Theory, Measurement, and Applications, Vol. 57, pp. 413-464, 1996.

[10] Al-Mossawy, M., Demiral, B., and Raja, D., "Foam Dynamics in Porous Media and its Applications in Enhanced Oil Recovery: Review", International Journal of Recent Research \& Applied Studies, Vol. 7, No. 4, pp. 351-359, 2011.

[11] Rafati, R., Hamidi, H., Idris, A. K., and Manan, M.A., “Application of Sustainable Foaming Agents to Control the Mobility of Carbon Dioxide in Enhanced Oil Recovery”, Egyptian Journal of Petroleum, Vol. 21, No. 2, pp. 155-163, 2012.

[12] Simjoo, M., Dong, Y., Andrianov, A., Talanana, M., and Zitha, P., “CT Scan Study of Immiscible Foam Flow in Porous Media for Enhancing Oil Recovery”, Industrial \& Engineering Chemistry Research, Vol. 52, No. 18, pp. 6221-6233, 2013.

[13] Talebian, S.H., Masoudi, R., Tan, I.M., and Zitha, P.L.J., "Foam Assisted $\mathrm{CO}_{2}$-EOR: A Review of Concept, Challenges, and Future Prospects", Journal of Petroleum Science and Engineering, Vol. 120, pp. 202-215, 2014.
[14] Cubillos, H., Montes, J., Prieto, C., and Romero, P., “Assessment of Foam for GOR Control to Optimize Miscible Gas Injection Recovery", SPE Improved Oil Recovery Symposium, Tulsa, Oklahoma, USA, 14-18 April, 2012.

[15] Farajzadeh, R., Andrianov, A., Krastev, R., Hirasaki, G., and Rossen, W.R., "Foam-Oil Interaction in Porous Media: Implications for Foam Assisted Enhanced Oil Recovery", Advances in Colloid and Interface Science, Vol. 183, pp. 1-13, 2012.

[16] Gao, B., and Sharma, M.M., “A New Family of Anionic Surfactants for EOR Applications", SPE Annual Technical Conference and Exhibition, San Antonio, Texas, USA, 8-10 October, 2012.

[17] Saint-Jalmes, A., Peugeot, M.-L., Ferraz, H., and Langevin, D., "Differences Between Protein and Surfactant Foams: Microscopic Properties, Stability and Coarsening", Colloids and Surfaces A: Physicochemical and Engineering Aspects, Volume 263, Nos. 1-3, pp. 219-225, 2005. 